\title{
Anatomical Study of the Facial Recess with Implications in Round Window Visibility for Cochlear Implantation: Personal Observations and Review of the Literature
}

\author{
Shraddha Jain ${ }^{1 \oplus}$ \\ PT Deshmukh¹ \\ Pooja Lakhotia \\ Mohnish Khatri ${ }^{1}$ \\ ${ }^{1}$ Department of Otorhinolaryngology, Datta Meghe Institute of
Medical Sciences (Deemed to be University), Jawaharlal Nehru
Medical College, Maharashtra, India \\ Int Arch Otorhinolaryngol 2019;23:e281-e291.
}

Sanika Kalambe ${ }^{1}$

Deepshikha Chandravanshi ${ }^{1}$

\begin{abstract}
Address for correspondence Shraddha Jain, MBBS, MS(ENT), PhD, Department of Otorhinolaryngology and Head Neck Surgery, Datta Meghe Institute of Medical Sciences (Deemed to be University), Jawaharlal Nehru Medical College, Sawangi (Meghe), Wardha, Maharashtra 442005, India (e-mail: sjain_med@yahoo.co.in).
\end{abstract}

\begin{abstract}
Keywords

- facial nerve

- round window membrane

- cochlear implantation

- chorda tympani nerve

Introduction Posterior tympanotomy through facial recess (FR) is the conventional and most preferred approach to facilitate cochlear implantation, especially when the electrode is inserted through the round window. The complications of the FR approach can be minimized by proper understanding of the anatomy of the FR.

Objective The present study was undertaken to assess the various parameters of FR and round window visibility, which may be of relevance for cochlear implant surgery. Methods Thirty-five normal wet human cadaveric temporal bones were studied by dissection for anatomy of FR and posterior tympanum. Photographs were taken with an 18 megapixels digital camera, which were then imported to a computer to determine various parameters.

Results The mean distance from the take-off point/crotch of the chorda tympani nerve (CTN) to the stylomastoid foramen was $4.08 \pm 0.8 \mathrm{~mm}$ (range of 2.06-5.5 mm). The variations in the course of the CTN included origin at the level of the lateral semicircular canal. The mean chorda-facial angle in our study was $26.91^{\circ} \pm 1.19^{\circ}$, with a range of $25^{\circ}$ to $28.69^{\circ}$. The mean FR length ranged between $9.4 \mathrm{~mm}$ and $18.56 \mathrm{~mm}$ (mean of $12.41 \pm 2.91 \mathrm{~mm}$ ) and varied with the origin of the CTN and pneumatization of temporal bone. The average maximum width of the FR was $2.93 \pm 0.4 \mathrm{~mm}$ (range $2.24-3.45 \mathrm{~mm}$ ) and the mean width of the FR at the level of the round window was $2.65 \pm 0.41 \mathrm{~mm}$.

Conclusion The FR approach provides good access to the round window membrane in all cases. In some cases, table adjustment is required.
\end{abstract}

\section{Introduction}

Posterior tympanotomy through facial recess (FR) is the conventional and most preferred approach to facilitate cochlear implantation $(\mathrm{CI})$, especially when the electrode is

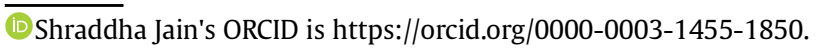

inserted through the round window. ${ }^{1}$ There is lot of debate about the best site of electrode insertion viz round window versus cochleostomy. ${ }^{2-9}$ Moreover, different approaches have been proposed to improve visualization, ease of electrode insertion and, more recently, for emphasis on preservation of residual hearing to provide the potential benefit of combined electric and acoustic auditory stimulation. ${ }^{10,11}$ received

May 1, 2018

accepted

October 6, 2018
DOI https://doi.org/

10.1055/s-0038-1676100. ISSN 1809-9777.
Copyright $\odot 2019$ by Thieme Revinter

Publicações Ltda, Rio de Janeiro, Brazil
License terms

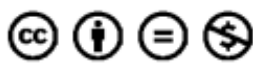


The view of the round window is best obtained by FR, though it has its own limitations. ${ }^{1}$ The three main approaches for $\mathrm{CI}$ are the classic approach, which uses the FR; the suprameatal approach (SMA), which does not require mastoidectomy and uses the creation of a tunnel over the facial nerve (FN) to enter the middle ear; and the endomeatal approach (EMA), which is based on the completion of a groove in the posterior wall of external auditory canal. ${ }^{12}$

In a study comparing the complications of these different methods, the FR technique had the lowest rate of major complications (1.1\%). ${ }^{12}$ The potential complication of the FR approach is paralysis of the FN and/or the chorda tympani nerve (CTN), which though rare, is of serious concern. However, Zernotti et al believed that FN stimulation occurs after implant programming and that sometimes, the electrodes need to be disconnected. ${ }^{12}$ In general, this complication is unrelated to the proximity of the implant to the Fallopian canal; in other words, it is unrelated to the type of approach used. Instead, it is linked with the proximity of the optic capsule to the intracranial FN (which is quite common among patients whose optic capsules are in the spongiosis or "spongy bone" phase of otosclerosis). The complications of the FR approach can be minimized by proper understanding of the anatomy of the FR. There is lot of variability in the origin of the chorda tympani above stylomastoid foramen. ${ }^{13-15}$ Hence, the CTN is potentially vulnerable in all CI surgeries. Unfavorable anatomy of the FN also places the FN at risk. The visibility of the round window niche through posterior tympanotomy is not always complete. ${ }^{16,17}$

There are very few cadaveric studies from India, which have attempted to look into the anatomy of the FR and round window visibility, as well as their implications in CI surgery. Hence, the present study was undertaken in adult wet cadaveric temporal bones to assess the various parameters of FR and round window visibility, which may be of relevance for $\mathrm{CI}$.

\section{Method}

Thirty-five normal wet human cadaveric temporal bones were studied by dissection for anatomy of FR and posterior tympanum. The study was approved by the Institutional Ethics Committee. Each temporal bone was mounted on the temporal bone holder and using standard otosurgical instruments, dissections were done on Carl Zeiss OPMI PICO (Carl Zeiss AG, Oberkochen, Germany) microscope under magnification. The bones were dissected with a motor drill, starting from McEwan's triangle, after the periosteum over the mastoid bone was removed, and the mastoid cortex was exposed. Then a complete mastoidectomy was performed. The overlying skin and bony structures of the external auditory canal were removed. Posterior tympanotomy was then performed. For this, first, the mastoid segment of the FN was skeletonized leaving a small incus bridge intact. Then, the chorda tympani was dissected from the takeoff point (mastoid segment) of the FN up to the point where it entered the middle ear. The FR was thus delineated. The dissected bones were photographed with an 18 megapixels digital camera. The photographs were then imported to a computer to determine the following para- meters using ScopyDoc version 8.0.0.22 software (Medsynaptic PVT, LTD, Pune, India) after proper calibration and $1 \mathrm{x}$ magnification.

1. The angle between the FN and the CTN.

2. The distance between the take-off point of the chorda tympani/crotch and the posterior-most prominent point of the short process of the incus (PPP-SPI).

3. Distance from the take-off point of CTN/crotch of CTN to the stylomastoid foramen.

4. The location of maximum width of the FR into short process of incus and the crotch of CTN.

5. The maximum width of the FR.

Posterior tympanotomy was now performed with a $0.7 \mathrm{~mm}$ diamond burr to visualize the round window niche, round window, stapes and pyramid after removing the tympanic membrane.

The visibility of round window was assessed through the posterior tympanotomy and then, further measurements were made after removal of incus and stapes suprastructure, in the same manner and at same magnification. Further measurements were taken to find some correlation of these with unfavorable anatomy of round window, with possible implications for $\mathrm{CI}$.

6 . The width of the FR at the level of round window.

\section{Results}

1. Distance from the take-off point of CTN/crotch of CTN to the stylomastoid foramen.

There was variation in the origin of the CTN and hence, in the distance from the take-off point or crotch of CTN to the stylomastoid foramen, with a mean of $4.08 \pm 0.8 \mathrm{~mm}$ and range of 2.06 to $5.5 \mathrm{~mm}$.

2. Variations in the course of chorda tympani

Out of the 35 temporal bones dissected, 6 showed major variations in the course of the CTN. Four showed bifurcation of chorda tympani at the level of origin itself from the vertical segment of the FN, one arose at the level of lateral semicircular canal with chorda tympani crossing above the stapes and hence non-existent FR. In one case, it branched into the posterior canal wall. (-Fig. 1, 2)

3. The angle between the FN and the CTN

The mean chorda-facial angle in our study was $26.91^{\circ} \pm 1.19^{\circ}$ with range of $25^{\circ}$ to $28.69^{\circ}$ (-Fig. 3)

4. The length of the FR/distance between the take-off point of the chorda tympani/crotch and the PPP-SPI.

There was lot of variation in the length of the FR, as measured by the distance between the crotch and the PPPSPI in our study, and it was found to range between $9.4 \mathrm{~mm}$ and $18.56 \mathrm{~mm}$ with a mean of $12.41 \pm 2.91 \mathrm{~mm}$. (-Fig. 4A, B) This showed a positive correlation with mastoid pneumatization, with greater FR length being found in pneumatized temporal bones as compared with sclerotic and diploic temporal bones.

5. Correlation of the angle between the FN-CTN and FR length (distance between the crotch and the PPP-SPI)

By using Pearson correlation coefficient, a statistically significant positive correlation was found between the 


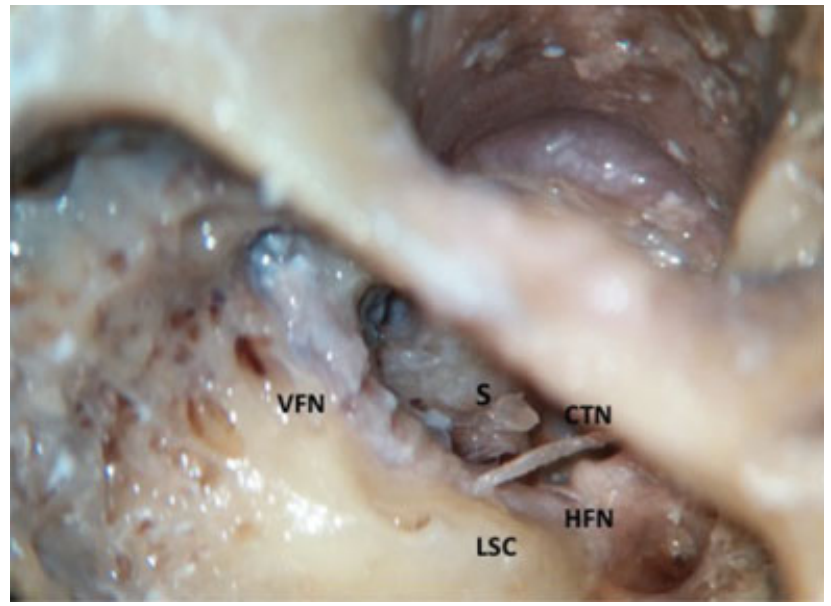

Fig. 1 Variation in origin of chorda tympani nerve at the level of lateral semicircular canal. Abbreviations: CTN, chorda tympani nerve; HFN, horizontal facial nerve; LSC, lateral semicircular canal; S, Stapes; VFN, vertical facial nerve. angle between the FN-CTN and FR length (the distance between crotch and the PPP-SPI) ( $r=0.607, p$-value $=0.0001)$; that is, the cadavers with larger distance between the crotch and the PPP-SPI had a greater angle between the FN and the CTN. (-Table 1, - Fig. 5)

6. The maximum width of the FR.

In our study, average maximum width of FR was $2.93 \pm 0.4 \mathrm{~mm}$, and, across different bones, the maximum FR width ranged from 2.24 to $3.45 \mathrm{~mm}$. We did not find any case with FR width less than $1 \mathrm{~mm}$. (-Fig. 6)

7. Correlation between the angle between the FN-CTN and maximum width of the FR with mastoid pneumatization.

By using Pearson correlation coefficient, a statistically significant positive correlation was found between the angle between the FN-CTN and the maximum width of the FR $(\mathrm{r}=0.872, p$-value $=0.0001)$; that is, as the angle between the FN and the CTN increased, the maximum width of the FR was also found to increase. (-Table 2, - Fig. 7)

In our study, the distance between the crotch and the PPP-SPI (FR length), the angle between the FN-CTN and the maximum width of FR were found to show higher

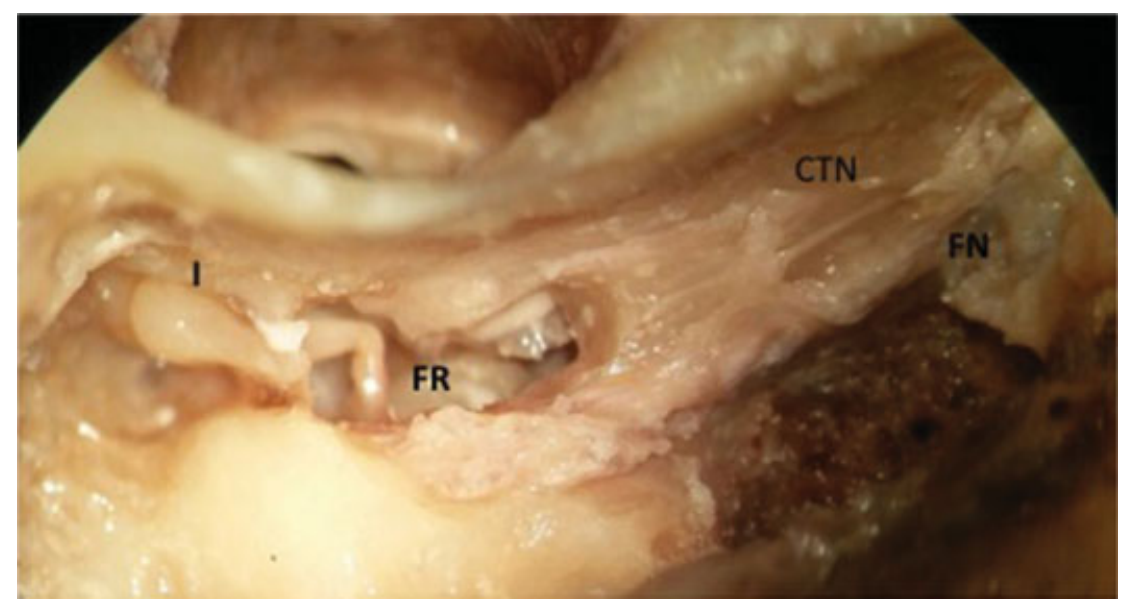

Fig. 2 Variation in course of chorda tympani nerve showing bifurcation from the origin. Abbreviations: CTN, chorda tympani nerve; FN, facial nerve; FR, facial recess; I, incus.

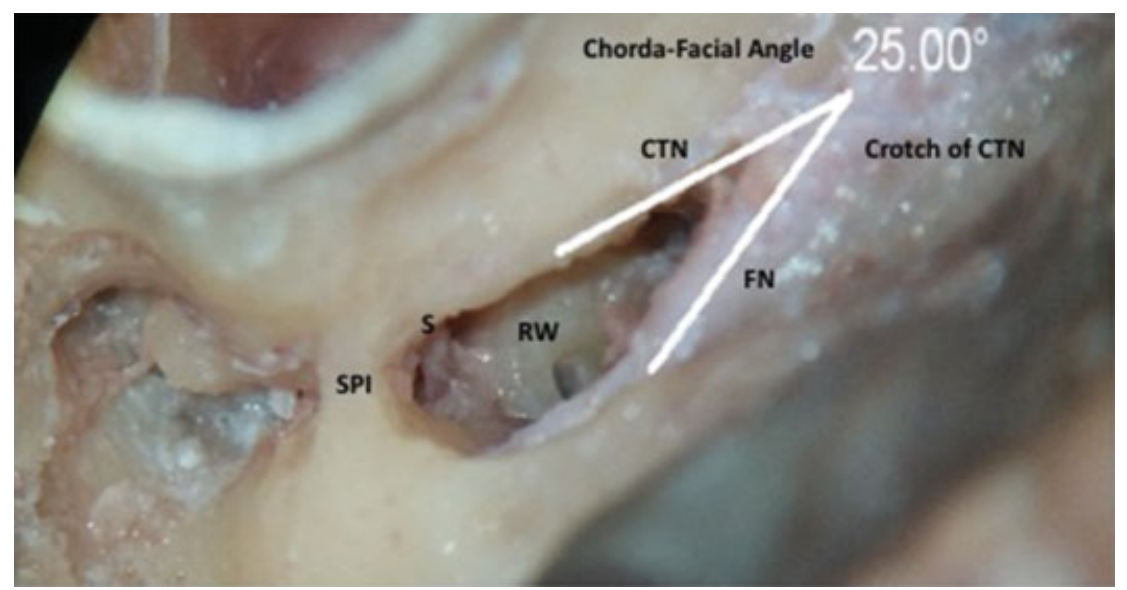

Fig. 3 Picture showing facial recess with chorda-facial angle of $25^{\circ}$ with the vertical facial nerve. Abbreviations: CTN, chorda tympani nerve; FN, facial nerve; RW, round window; S, stapes; SPI, short process of incus. 

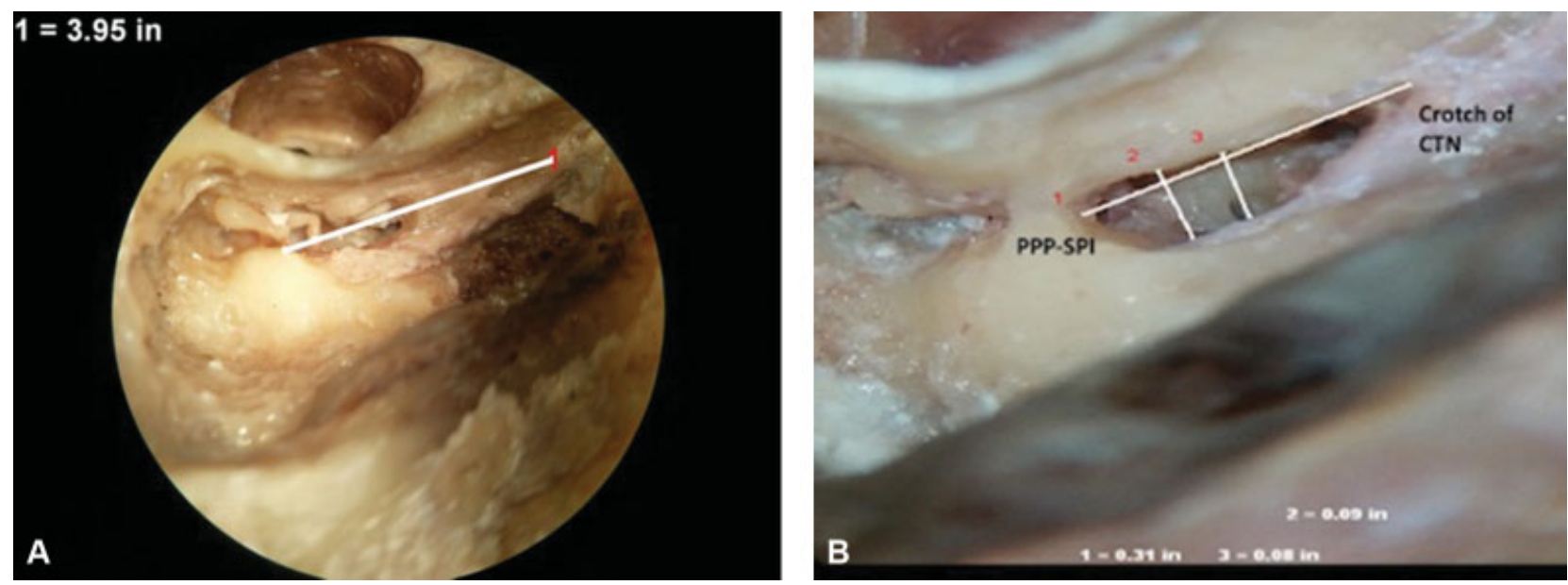

Fig. 4 (A, B) Photographs showing the facial recess with variable facial recess length (distance between the take-off point of the chorda tympani/crotch and the posteriormost prominent point of the short process of the incus [PPP-SPI]). (A) is the case of a well pneumatized mastoid with long facial recess length. (B) is a case of sclerotic/contracted mastoid with small facial recess length. (B) also shows the maximum width of facial recess and width of facial recess at the level of round window.

Table 1 Pearson correlation coefficient between the angle between the facial nerve and chorda tympani nerve and facial recess length (distance between the crotch and the posteriormost prominent point of the short process of the incus)

\begin{tabular}{|l|l|l|l|l|l|}
\hline & Mean & SD & N & Correlation ' $r$ ' & $p$-value \\
\hline Angle between the FN-CTN & 26.90 & 1.19 & 34 & 0.607 & $0.0001, \mathrm{~S}$ \\
\cline { 1 - 4 } Distance between crotch and PPP-SPI & 12.41 & 2.91 & 34 & & \\
\hline
\end{tabular}

Abbreviations: FN-CTN, facial nerve and chorda tympani nerve; PPP-SPI, posteriormost prominent point of the short process of the incus; S, stands for - Statistically significant; SD, standard deviation.

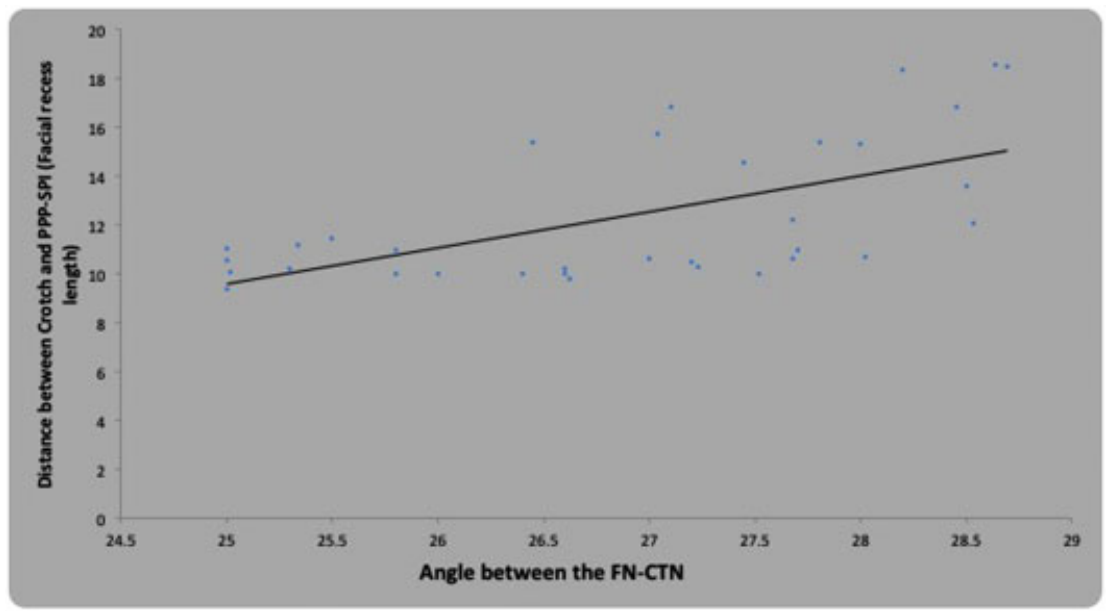

Fig. 5 Correlation between the angle between the facial nerve of the chorda tympani nerve and the distance between the crotch and the posteriormost prominent point of the short process of the incus. $(r=0.607, p$-value $=0.0001)$.

values in pneumatized temporal bones as compared with sclerotic and diploic temporal bones.

8. The width of FR at the level of the round window.

The mean width of the FR at the level of the round window, in our study, was $2.65 \pm 0.41 \mathrm{~mm}$. (-Fig. 6)

9. The location of maximum width of the FR into the short process of incus and the crotch of the CTN.

The average distance of location of maximum width of the FR from the short process of incus in our study was $3.44 \pm 0.4 \mathrm{~mm}$.
The average distance of location of maximum width of the FR into the crotch of the CTN, in our study, was $9.08 \pm 2.6 \mathrm{~mm}$. (-Fig. 6)

\section{Discussion}

In the present study, variations in various anatomical parameters of FR, relevant to CI by posterior tympanotomy approach, were studied and compared with other studies. These include variations in FR length, maximum FR width, FR width at level of round window, RW visibility through FR. 


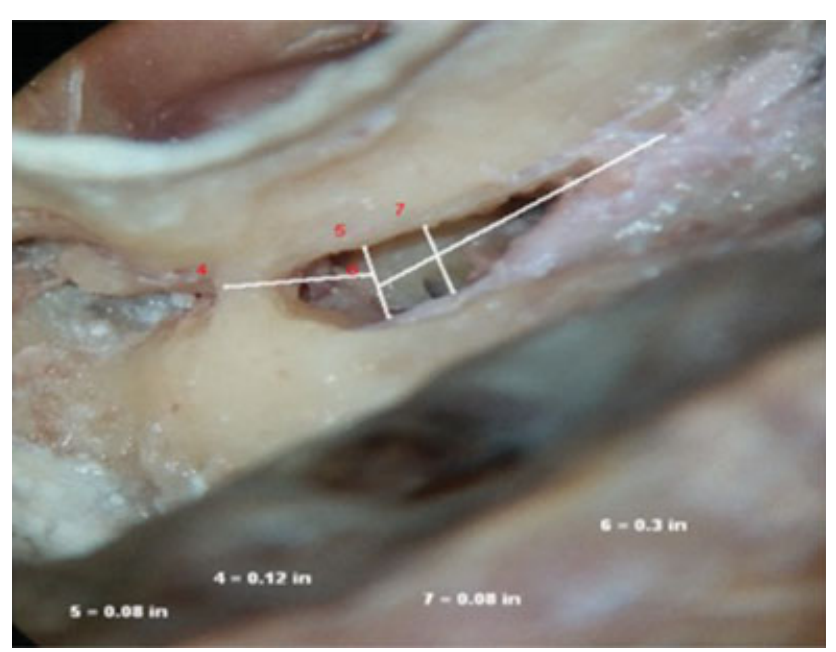

Fig. 6 Photograph showing facial recess with location of maximum width of the facial recess into short process of incus and the crotch of chorda tympani nerve. It also shows the width of facial recess at the level of round window.

Table 2 Pearson correlation coefficient between the angle between the facial nerve and chorda tympani nerve and maximum width of facial recess

\begin{tabular}{|l|l|l|l|l|l|}
\hline & Mean & SD & $\mathrm{N}$ & $\begin{array}{l}\text { Correlation } \\
\text { 'r' }\end{array}$ & $p$-value \\
\hline $\begin{array}{l}\text { Angle } \\
\text { between } \\
\text { the FN-CTN }\end{array}$ & 26.90 & 1.19 & 34 & 0.872 & $\begin{array}{l}0.0001, \\
\text { S }\end{array}$ \\
\cline { 1 - 4 } $\begin{array}{l}\text { Max. width } \\
\text { of FR }\end{array}$ & 2.93 & 0.41 & 34 & & \\
\hline
\end{tabular}

Abbreviations: FN-CTN, facial nerve and chorda tympani nerve; FR, facial recess; S, stands for - Statistically significant; SD, standard deviation.

These parameters are likely to be affected by variations in the origin and course of CTN. Prior knowledge of these variations is important, to avoid complications of FN and CTN injury. In view of $\mathrm{Cl}$ surgeries being routinely performed now, it is the need of the hour to develop data for each racial group, so that decision regarding ideal surgical approach and electrode designing can be undertaken. With these goals in mind, we have compared our findings with the existing literature.

\section{a) Distance from take-off point of CTN/crotch of CTN to the stylomastoid foramen (SMF)}

In our study, there was variation in the origin of the CTN and hence, in the distance from take-off point or crotch of CTN to stylomastoid foramen, with a mean of $4.08 \pm 0.8 \mathrm{~mm}$ and range of 2.06 to $5.5 \mathrm{~mm}$. - Table 3 shows a comparison with different studies. This distance is similar to the mean distance shown in the study of all the other authors.

As early as 1955, Haynes had observed that one feature of the FN that varies considerably is the point at which the chorda tympani joins the parent nerve. ${ }^{25}$ He said that contrary to the belief that the chorda tympani joins the FN at a fixed distance above the stylomastoid foramen, it was not so. In one specimen, he found the chorda tympani starting its recurrent course almost outside the stylomastoid foramen, whereas in others, it joined the trunk almost at the level of the semicircular canal. We also encountered one similar origin of CTN at the level of the lateral semicircular canal.

Gray's Anatomy describes the CTN arising from the FN $6 \mathrm{~mm}$ above the stylomastoid foramen. ${ }^{15}$ In 1967, Durcan et al reported the distance from the chorda tympani to the stylomastoid foramen to be $6 \mathrm{~mm} .{ }^{18}$ During 100 temporal bone dissections, Kullman et al noted the nerve to arise from between $1.2 \mathrm{~mm}$ distal to $10.9 \mathrm{~mm}$ proximal to the stylomastoid foramen, with a mean of $5.3 \mathrm{~mm} .{ }^{19}$ Muren et al noted a mean distance from the origin of the CTN to the SMF to be $4.8 \mathrm{~mm}$ (range $0-10.0 \mathrm{~mm}$ ). ${ }^{20}$ Proctor and Nager noted that the origin of chorda tympani can vary from $1 \mathrm{~mm}$ distal to $11 \mathrm{~mm}$ proximal to the stylomastoid foramen, with a mean of $5 \mathrm{~mm} .{ }^{21}$ In their study of 25 temporal bone dissection, Yadav et al found the distance to range from 2 to $12 \mathrm{~mm}$, with a mean distance of $6.2 \mathrm{~mm} .{ }^{22}$ Maru et al found CTN with intratemporal origin to arise at a mean of $7.2 \mathrm{~mm}$ (range $0.2-9.7 \mathrm{~mm}$ ) proximal the stylomastoid foramen. ${ }^{23}$ Trost et al described

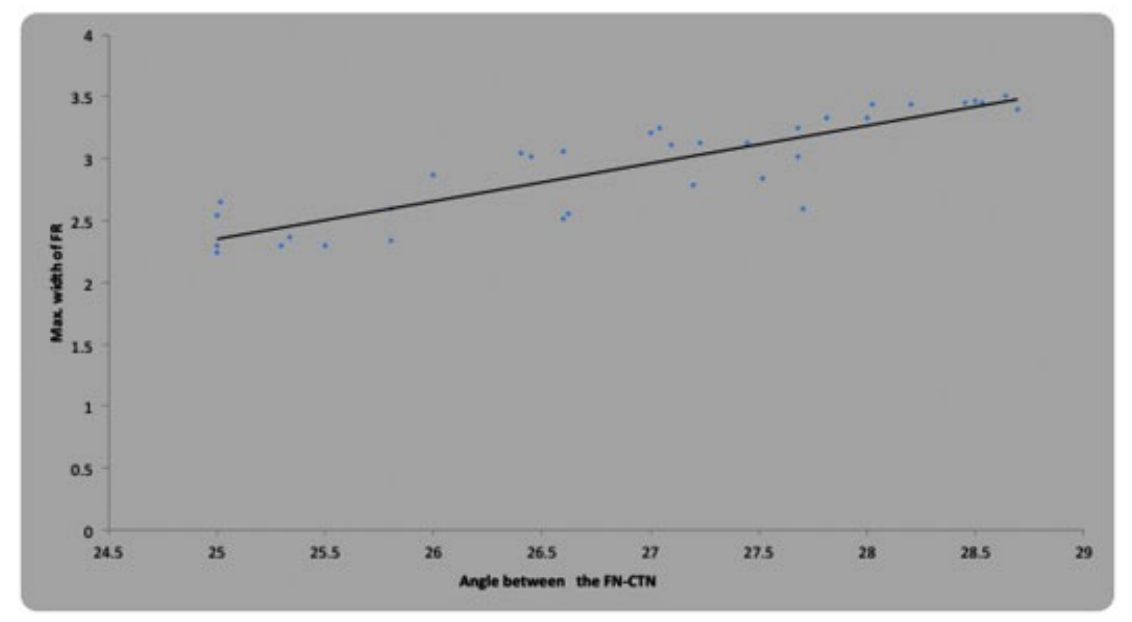

Fig. 7 Correlation between angle between the facial nerve and chorda tympani nerve and maximum width of the facial recess $(r=0.872, p$ value $=0.0001)$. 
Table 3 Distance between the chorda tympani nerve origin and the stylomastoid foramen. (comparison of present study with other studies)

\begin{tabular}{|c|c|c|c|c|}
\hline Author & Year & $\begin{array}{l}\text { Total no of } \\
\text { bones/ears } \\
\text { operated }\end{array}$ & $\begin{array}{l}\text { Mean distance (mm) } \\
\text { from the crotch of } \\
\text { the CTN to the SMF }\end{array}$ & $\begin{array}{l}\text { Range } \\
(\mathrm{mm})\end{array}$ \\
\hline Durcan $^{18}$ et al. & 1967 & NM & $6 \mathrm{~mm}$ & \\
\hline Kullman GL et al ${ }^{19}$ & 1971 & 100 bones & $5.3 \mathrm{~mm}$ & $1.2 \mathrm{~mm}$ distal-10.9 $\mathrm{mm}$ proximal to SMF \\
\hline Muren $\mathrm{C}$ et $\mathrm{al}^{20}$ & 1990 & 26 bones & $4.8 \mathrm{~mm}$ & $0 \mathrm{~mm}-10.0 \mathrm{~mm}$ \\
\hline Proctor and Nager ${ }^{21}$ & 1991 & NM & $5 \mathrm{~mm}$ & $1 \mathrm{~mm}$ distal-11 mm proximal to SMF \\
\hline Yadav SPS et al. ${ }^{22}$ & 2006 & 25 bones & $6.2 \mathrm{~mm}( \pm 2.66 \mathrm{~mm})$ & $2 \mathrm{~mm}-12 \mathrm{~mm}$ \\
\hline Maru et $\mathrm{al}^{23}$ & 2010 & & $7.2 \mathrm{~mm}$ & $0.2 \mathrm{~mm}-9.7 \mathrm{~mm}$ \\
\hline Trost et al ${ }^{14}$ & 2011 & & 2 or $3 \mathrm{~cm}$ & \\
\hline Liu et al $^{13}$ & 2012 & & $13.32 \mathrm{~mm}$ & $5.93 \mathrm{~mm}-21.63 \mathrm{~mm}$ \\
\hline Zou et $\mathrm{al}^{24}$ & 2012 & & $2.67 \mathrm{~mm}(+/-0.51 \mathrm{~mm})$ & \\
\hline Our study & 2017 & 35 bones & $4.08 \pm 0.8 \mathrm{~mm}$ & $2.06-5.5 \mathrm{~mm}$ \\
\hline
\end{tabular}

Abbreviations: CTN, chorda tympani nerve; SMF, stylomastoid foramen.

the chorda tympani emerging 2 or $3 \mathrm{~cm}$ above the stylomastoid foramen but only made measurements of the chorda tympani in the infratemporal fossa region. ${ }^{14}$ Liu et al described chorda tympani as a very fine nerve $(0.44 \mathrm{~mm}$ in diameter within the tympanic cavity), and the distance between the chorda tympani and stylomastoid foramen as ranging from $5.93 \mathrm{~mm}$ to $21.63 \mathrm{~mm}$, with the average distance being $13.32 \mathrm{~mm} .{ }^{13}$ Zou et al found the distance from the crotch of the CTN to the stylomastoid foramen to be $2.67+/-0.51 \mathrm{~mm} .^{24}$

From the above, it can be seen that the variation in origin of the CTN will give rise to lots of variations in the dimensions of the FR, which may have implications in cochlear implant surgery.

In our study, the site of origin of the CTN was $4.08 \pm 0.8 \mathrm{~mm}$, whereas it was 4 to $8 \mathrm{~mm}$ proximal to the stylomastoid foramen in 64\% of temporal bones in the study conducted by Yadav et al. Still, Kullman et al reported that CTN arose $3 \mathrm{~mm}$ proximal to stylomastoid foramen in $75 \%$ of the cases they studied. ${ }^{19,22}$

As there is lot of variability in the origin of the CTN, mean values are not much significant in this case. The range of variability should be known to the cochlear implant surgeon to avoid inadvertent damage to the CTN. Hence, it is important to report CTN injury in $\mathrm{CI}$, so that real complication rate of FR approach can be known.

\section{b) Variations in the course of chorda tympani}

In our study, out of 35 temporal bones dissected, 6 showed major variations in the course of the CTN. Four showed bifurcation of chorda tympani at the level of origin itself from the vertical segment of the FN and one arose at the level of lateral semicircular canal with chorda tympani crossing above the stapes and hence non-existent FR. In one case, it branched into the posterior canal wall. ( - Table 4)

As early as 1955, Haynes had observed one feature of the facial nerve that varies considerably was the point at which the chorda tympani joins the parent nerve. 25 He said that contrary to the belief that the chorda tympani joins the facial nerve at a fixed distance above the stylo-mastoid foramen, it was not so. In one specimen, he found the chorda tympani starting its recurrent course almost outside the stylomastoid foramen whereas in other it joined the trunk almost at the level of the semicircular

Table 4 Variations in the course of the chorda tympani nerve. (comparison of present study with previous studies)

\begin{tabular}{|l|l|l|l|l|}
\hline Author & Year & $\begin{array}{l}\text { Total no. of } \\
\text { bones/ear } \\
\text { operated }\end{array}$ & $\begin{array}{l}\text { No. of cases } \\
\text { of variation }\end{array}$ & Type of variation of chorda tympani \\
\hline Haynes $^{25}$ & 1955 & NM & 1 case & $\begin{array}{l}\text { Chorda tympani arose outside the stylomastoid } \\
\text { foramen. }\end{array}$ \\
\cline { 3 - 5 } & & 1 case & $\begin{array}{l}\text { Chorda tympani joined the main trunk almost at the level } \\
\text { of the semicircular canal. }\end{array}$ \\
\hline Minnigerode $^{26,27}$ & 1965 & NM & 1 case & Branch of chorda tympani in middle ear \\
\hline Histelberger and House $^{28}$ & 1966 & NM & 1 case & A branch running through the posterior canal wall \\
\hline Durcan et al. ${ }^{18}$ & 1967 & NM & 3 cases & Bifurcation of chorda tympani \\
\hline Present study & 2017 & 35 & 4 cases & Bifurcation of chorda tympani \\
\cline { 3 - 5 } & & & 1 case & Arose at the level of lateral semicircular canal \\
\cline { 3 - 5 } & & & 1 case & A branch to the posterior canal wall \\
\hline
\end{tabular}


Table 5 Chorda facial angle (comparison of present study with previous studies)

\begin{tabular}{|l|l|l|l|l|}
\hline Author & Year & $\begin{array}{l}\text { Total no. of bones } \\
\text { ear operated }\end{array}$ & Type of study & $\begin{array}{l}\text { Mean chorda facial angle }\left(^{\circ}\right) \\
( \pm \text { SD })\end{array}$ \\
\hline Zhu Y et al & 2008 & $\begin{array}{l}40(20 \text { cadavers) } \\
\text { temporal bones }\end{array}$ & Cadaveric & 24.8 degrees \\
\hline Calli et al $^{31}$ & 2010 & 30 & Cadaveric & $23.58^{\circ}( \pm 6.84)$ \\
\hline Măru N et al & 2010 & 35 & Cadaveric & $26-35^{\circ}$ \\
\hline Jeon EJ et al & 2013 & 20 & Radiologic (CT) in patients & $18.40^{\circ} \pm 1.05^{\circ}$ \\
\hline Diogo l et al & 2016 & 65 & $\begin{array}{l}\text { Radiologic (CBCT) in } \\
\text { postoperative patients }\end{array}$ & $22.6 \pm 9.5^{\circ}$ \\
\hline Present study & 2017 & 35 & Cadaveric & $26.91^{\circ} \pm 1.19^{\circ}\left(\right.$ range $\left.25^{\circ}-28.69^{\circ}\right)$ \\
\hline
\end{tabular}

Abbreviations: CBCT, cone beam computed tomography; $\mathrm{CT}$, computed tomography; SD, standard deviation.

canal. We also encountered one similar origin of chorda tympani nerve at the level of lateral semicircular canal.

In 1965, Minnigerode reported a case in which the chorda tympani, as it crossed the long process of incus, gave off a small branch which was distributed to the posterosuperior quadrant of tympanic membrane. He suggested that this nerve may be related to sensory "Hautsinnesnerven" of lower vertebrates. $^{26,27}$ Histelberger and House demonstrated a branch from the chorda tympani running through the posterior canal wall to the skin of the posterior aspect of external auditory canal. $^{28}$ In 1967, Durcan et al reported 3 instances of bifurcation of CTN. ${ }^{18}$ Nager and Proctor described that chorda tympani having extratemporal origin had an incidence of only $2 \% .{ }^{21}$ Low noted an incidence of extratemporal origin higher than $50 \%$ in Chinese specimens. ${ }^{29}$ Maru et al had findings similar to those of Nager and Proctor, with and incidence of $5.7 \%$ of origin of CTN outside the stylomastoid foramen in 2 specimens. ${ }^{21,23}$

\section{c) Chorda facial angle}

The ean chorda facial angle in our study was $26.91^{\circ} \pm 1.19^{\circ}$, with range of $25^{\circ}$ to $28.69^{\circ}$. (-Table 5)

Zhu et al dissected 40 human temporal bones of 20 voluntary bone donors and relative anatomical data of operation were observed and measured under operating microscope through posterior tympanum approach entering posterior tympanum. ${ }^{30}$ They found the angle of between the CTN and the FN to be 24.8 degrees. They had concluded that the position of anatomic structure in the middle ear was constant and the relationship, including distance and angle between anatomic structures, changed in limited region. The anatomical parameters provide a reference value for avoiding injury during the operation.

Calli et al made the use of computer-aided design software to measure the angle between the FN and the CTN in 30 cadaveric adult temporal bones. ${ }^{31}$ The mean angle was $23.58^{\circ}( \pm 6.84)$. Their important finding was that there was a correlation between the distance between the take-off point of the chorda tympani and the PPP-SPI and the chorda facial angle, with an inverse relation; that is, the former tended to be greater when the angle was less than the mean and vice versa. This trend approached but did not quite reach statistical significance $(r=-0.248, p=0.059$ ) in their study.
Maru et al studied 35 temporal bones harvested from cadavers or human dried skulls, after dissecting under the microscope or sectioning in different planes, with an electric saw and diamond disc. ${ }^{23}$ The temporal bones were analyzed on a stereomicroscope and photographed with a digital camera. The images were then filtered and corrected with the image analysis software DP-Soft. Measurements on Xand Y-axis (horizontal plane) were performed using a caliber and the software measuring features. They found the angle between the CTN at its emerging and the mastoid segment of the facial nerve to vary between 26 and $35^{\circ}$.

Jeon et al evaluated the surgical and radiologic anatomy of a cochleostomy produced via posterior tympanotomy for $\mathrm{CI}^{32}$ Twenty computed tomography (CT) images of the temporal bones from patients aged between 20 and 60 years were selected. Three-dimensional (3D) reconstructed images were obtained using high-resolution axial temporal bone CT scans. Eight points were used to evaluate the surgical anatomy of the posterior tympanotomy and cochleostomy. The length of lines between the points and the angles between the lines were measured. The mean angle of $A B C$ (angle at which the CTN branched from the FN) was $18.40^{\circ} \pm 1.05^{\circ}$ in their study. Their study results were in favor of using 3D imaging of the FR and round window to identify the FR before surgery. This may help to avoid injury to the CTN and FN during posterior tympanotomy and to facilitate the insertion of the electrode array during CI by creation of a wide posterior tympanotomy.

\section{d) The distance between the take-off point of the chorda tympani/crotch and the PPP-SPI}

In our study, there was great variation in the distance between the crotch and the PPP-SPI, which was found to range from $9.4 \mathrm{~mm}$ to $18.56 \mathrm{~mm}$, with a mean of $12.41 \pm 2.91 \mathrm{~mm}$. This results in variability in the size of the FR and hence, in the visibility of the round window membrane. The FR length appeared to have positive correlation with mastoid pneumatization, being higher in more pneumatized mastoid bones.

Calli et al studied the distance between the take-off point of the chorda tympani and the PPP-SPI in 30 cadaveric adult temporal bones and found it to be $7.78 \mathrm{~mm}( \pm 2.68){ }^{31}$ 
Zou et al found the distance between the SPI and the crotch of the CTN to be $15.22(+/-0.83) \mathrm{mm}^{24}$

\section{e) The maximum width of the FR}

In our study, the average maximum width of FR was $2.93 \pm 0.4 \mathrm{~mm}$ and, across different bones, maximum FR width ranged from 2.24 to $3.45 \mathrm{~mm}$. We did not find any case with FR width less than $1 \mathrm{~mm}$.

This is similar to the findings reported by Su et al and Young et al, of FR width of 3.8 to $4.0 \mathrm{~mm}$. 34,35

Zou et al found the maximum width of the FR to be 2.73 $(+/-0.20) \mathrm{mm}^{24}$

Wang L et al and Wang LE et al, in their studies, found 32 patients with narrow FRs of less than $1.0 \mathrm{~mm}{ }^{36,37}$ The main reason for the narrow FR, according to them, was CTN retropositioning.

Wang et al dissected 16 human temporal bones of 8 adult cadaveric heads under surgical microscope through FR approach, and measured the relative anatomic structures, such as the bony entrance of the FR approach, the FN, stapes, round window, round window niche, pyramidal eminence, cochleariform process, etc. and analyzed the data statistically. ${ }^{38}$ They found the width of the bony entrance of the FR approach to be $(2.94+/-0.32) \mathrm{mm}$.

Jeon et al found the mean length of superior-inferior length of the posterior tympanotomy for $\mathrm{CI}$ was $6.48 \pm 0.26 \mathrm{~mm}$, while the width of the FR was $3.60 \pm 0.2 \mathrm{~mm}^{32}$

Vaid et al proposed a grading system based on a 10-point scoring chart of high resolution computed tomography (HRCT) and magnetic resonance imaging (MRI) findings in patients being assessed preoperatively for $\mathrm{CI}^{39}$ The FR anatomy was considered as one of the parameters of difficulty encountered during $\mathrm{CI}$, in which a narrow FR of $<3$ mm was considered unfavorable, whereas a wide FR of $>3$ mm was considered favorable.

In our study, the FR width ranged from 2.24 to $3.45 \mathrm{~mm}$, and we did not find any case with FR width less than $1 \mathrm{~mm}$. We agree with the findings of Vaid et al, in the the FR of $<3 \mathrm{~mm}$ is unfavorable.

We found a positive correlation between FR length, maximum width of FR and angle between FN and CTN. Moreover, we observed that the distance between the crotch and the PPP-SPI (FR length), the angle between the FN-CTN, and the maximum width of the FR were found to show higher values in pneumatized temporal bones as compared with sclerotic and diploic temporal bones. In our study, maximum effect of pneumatization of mastoid was seen to occur on that of the FR length, as this parameter showed maximum variation.

In a study by Young and Nadol, the height of the extended FR at the stapes level was $4.0 \mathrm{~mm}$ in those bones with good pneumatization and $3.87 \mathrm{~mm}$ in the bones with poor pneumatization. ${ }^{35}$ At the round window, they found the height of FR to be $3.0 \mathrm{~mm}$ in bones with good pneumatization and $3.05 \mathrm{~mm}$ in bones with poor pneumatization. However, no statistically significant difference between the measurements was obtained for height of FR at round window, or at stapes level, in bones with good and poor pneumatization.
They did not compare FR length or angle in bones with different pneumatization pattern.

From the above, we concluded that variation in the origin of CTN and pneumatization pattern can influence the size of the FR.

\section{f) The width of FR at level of round window}

The mean width of the FR at the level of the round window in our study was $2.65 \pm 0.41 \mathrm{~mm}$. Our results are comparable to those of other studies.

He et al conducted a study of the anatomy related to $\mathrm{CI}$ guided by HRCT. Six temporal bones were dissected according to the main steps of $\mathrm{CI}$ and scanned in axial and semilongitudinal planes by HRCT to observe the relationship between anatomy and HRCT. ${ }^{40}$ The width of the FR in dissection was $3.13(+/-0.34) \mathrm{mm}$ at the level of the round window, and 4.12 $(+/-0.44) \mathrm{mm}$ at the level of the oval window. The width of FR in HRCT was $3.20(+/-0.38) \mathrm{mm}$ at the level of round window, and $4.14(+/-0.47) \mathrm{mm}$ at the level of oval window. The whole course of the FN was visualized clearly in semilongitudinal plane. No statistically significant differences were found between the results of dissection and those of HRCT

The value of the width of the FR at the level of the round window was $2.24(+/-0.18) \mathrm{mm}$ in the study by Zou et al. ${ }^{24}$

Wang $L$ et al and Wang LE et al, in their studies, found 32 patients with narrow FRs, with the average width at the level of the round window being $0.85 \mathrm{~mm} .^{36,37}$ Hence, they described a new method of FR enlargement through suspending, ante displacing, and adhering the CTN to the posterior wall of the auditory canal to expose the round window, make the electrode insertion easier, and preserve the function of the FN and CTN in cases in which the narrowest distance between the FN and the CTN was less than $1.0 \mathrm{~mm}$.

The findings of our study were similar to those of Otzurk et al, who did not find a FR width of less than $1 \mathrm{~mm}$ in any of their 24 cadavers. ${ }^{17}$ They suggested a possibility of this difference being attributable to the dissection limits, which could be more advanced in a cadaver study than in real life.

\section{g) The location of maximum width of the FR into short process of incus and the crotch of CTN}

The average distance of location of maximum width of the FR from the SPI in our study was $3.44 \pm 0.4 \mathrm{~mm}$, and from the crotch of the CTN it was $9.08 \pm 2.6 \mathrm{~mm}$, respectively.

Zou et al found that the location of maximum width of the FR into the SPI and the crotch of CTN were $6.28(+/-0.41)$ $\mathrm{mm}$ and $9.81(+/-0.71) \mathrm{mm}$, respectively. ${ }^{24}$

\section{h) Round window visibility through FR}

We found that a thicker round window bony overhang was not associated with greater difficulty in accessing round window. It was the orientation and size of the round window (that is, how posterior and inferior it was), rather than thickness of the bony overhang, which better predicted the difficulty with round window access. 
In all our cases, FR was wide enough at the level of round window to get adequate exposure of round window niche and round window membrane for round window insertion of electrodes.

We observed that the cause of limited visibility of round window was, that the round window was positioned posteromedial to the FN and that CTN ante placement, as advocated by Wang et al would not improve round window exposure. ${ }^{36,37}$ In all the cadavers in our study, round window exposure was obtained but in some, additional positioning of the table was required. The FN appeared to be at risk in cases of posteriorly placed round window. In such cases, prior adjustments of the table may help prevent damage. Facial recess enlargement by sacrificing or repositioning CTN would offer no benefit in terms of visualization of round window niche or membrane. For this, we would recommend prior imaging to identify posteriorly placed round window niche. The findings of our study were similar to those of Otzurk et al, who also stated that the cause of limited visibility of RW in their series of all partially exposed round windows of cadavers was posteromedial placement of round window in relation to the FN and they felt that CTN ante placement would not improve round window exposure. ${ }^{17}$

In an anatomical study, Hamamoto et al favored cochleostomy insertion of electrodes as, according to them, reliable round window access could not be achieved by posterior tympanotomy through the FR. ${ }^{16}$ However, Otzurk et al found that total round window exposure could be achieved through the FR in most temporal bones (79.2\%). ${ }^{17}$ According to them, total exposure of the round window will allow round window insertion of the cochlear implant electrodes. They interpreted their results with maximum exposure of round window with microscope adjustment only. No table adjustment was mentioned in their study. We achieved near complete exposure of the round window niche in all (100\%) cases, with table adjustment in "head low" and "posterior tilt" position. Fixed radiologic landmarks may help identify a posteriorly placed round window niche but give an exaggerated picture of reallife problem situation. Hence, more studies need to be conducted on practical intraoperative situations correlated with radiologic determinants.

Leong et al reported that the round window was visible in more than 50 to $89 \%$ of adult and $78 \%$ of pediatric cases after an optimal posterior tympanotomy. ${ }^{41}$ In cases in which the round window niche cannot be totally exposed, attempting further dissection of the anatomic boundaries may cause injury to FN and/or CTN. Promontory cochleostomy anteroinferior to round window might be preferred in such cases.

This was in contrast to the results of Wang et al, who reported 32 cases with a width of FR narrower than $1 \mathrm{~mm}$, in which they suggested CTN ante placement to widen the FR and obtain adequate exposure of round window niche. ${ }^{36,37}$ These differences could be attributable to racial differences or limited sample.

In a previous study, Lee et al reported that the angle between the cortex of the external ear canal and the FN was highly correlated with visibility through posterior tympanotomy. ${ }^{42}$ They suggested that pneumatic mastoids, but not sclerotic mastoids, could have a more complex relationship with FR anatomy, including various other factors that were not considered in their study.

Pendem et al studied the accuracy of HRCT temporal bone measurements in predicting the actual visualization of round window niche as viewed through posterior tympanotomy (such as, FR) in a prospective study of 37 cochlear implant candidates, aged between 1 and 6 years old. ${ }^{43}$ The distance between the short process of incus and the round window niche and the distance between the oval window and the round window niche were measured preoperatively on sub-millimeter $(0.7 \mathrm{~mm})$ HRCT images. They classified the visibility of the round window niche based on the surgical view (that is, through posterior tympanotomy) during surgery into three types: 1) Type 1-fully visible, 2) Type 2partially visible, and 3) Type 3-difficult to visualize. The preoperative HRCT measurements were used to predict the type of visualization of round window niche before surgery and correlated with the findings during surgery.

We observed that cases of type-3 visibility (difficult to visualize) of round window niche, through posterior tympanotomy, are the ones with posteriorly and inferiorly placed round window niche. In such cases pre-operative identification by imaging may alert the surgeon and he may make necessary adjustments on the table to avoid nerve injury.

Another correlation in our study, was the distance between the crotch of the CTN and the posterior most portion of short process of incus, with the visibility of round window. If this distance is less, and round window is also inferior, it will further make exposure of wound window difficult, without injury to CTN or FN. As there was wide variation in this parameter in our study, narrow limits of FR between crotch and short process of incus could cause difficulty in exposure of round window.

\section{Comparison between the FRs of Children and Adults}

Eby studied the development of the FR, with its implications in $\mathrm{CI}^{44}$ The FR and the extended FR were measured in 123 temporal bones from 73 individuals ranging in age from 8 weeks in utero to 7 years after birth. The goals were to trace the development of the FR and to determine whether this area continued to grow into childhood. They observed that the FR enlarges throughout fetal life with the development of the facial canal and the tympanic annulus. Reichert cartilage, seen early in utero in the FR, gradually resorbs but may persist in the newborn. According to the author, in full-term infants, the FR reached $3.25 \mathrm{~mm}$ at the oval window and $2.62 \mathrm{~mm}$ at the round window. The extended FR reached $3.79 \mathrm{~mm}$ at the oval window and $3.04 \mathrm{~mm}$ at the round window. No statistically significant growth of the FR after birth could be demonstrated in the study. The data in Eby's study suggested that the FR is probably adult-sized at birth and should allow surgical access for $\mathrm{CI}$ in very young children.

Bielamowicz et al used serial sections of temporal bones to measure the surgical dimensions of the FR in order to evaluate the feasibility of $\mathrm{CI}$ in children. ${ }^{45}$ No statistically 
significant differences in the dimensions of the FR or the extended FR approaches were found between children and adults. The relationship between the facial and CTN and the annular plane exhibited no change with postnatal growth. These structures translate posteriorly and laterally toward the annular plane as they descend within the temporal bone. Therefore, according to the authors, the FR approach did not present greater hazard in a child than in an adult.

Tian and Zhang also got similar results in a study conducted on 32 pediatric cochlear implant recipients younger than 3 years. ${ }^{46}$ Before implantation, the FR was measured by HRCT and compared with direct anatomical measurement in implantation. There was no significant difference of the volume between the recipients in this study and the children in another group who were older than 7 years old ( $p>0.05$ ). They concluded that the FR is already adult-sized in children younger than 3 years old.

Lloyd et al, and later McRackan et al showed that the basal turn of the cochlea changed orientation with respect to the FR as an individual grows. ${ }^{47,48}$ They reported decrease of basal turn angle with regard to the sagittal plane with age. The data of McRackan et al, showed that the drilling trajectory was significantly closer to paralleling the lateral External Auditory Canal (EAC) in adults as compared with children $\left(19.40^{\circ}\right.$ versus $23.51^{\circ}$ respectively; $\left.p<0.001\right)$. This suggested that the surgeon's view of the round window through the FR was less obstructed in adults and more in-line with that view.

\section{Justification of the Study in Adult Temporal Bones and Areas of Future Research}

As previous studies have found, there were no statistically significant differences in the dimensions of the FR or the extended FR approaches between children and adults. ${ }^{44-46}$ Hence, the adult parameters can be applicable to the pediatric population as well. However, more surgical and radiologic studies need to be undertaken in children for applicability of these parameters in the pediatric population regarding cochlear orientation and round window visibility through the FR. ${ }^{47,48}$

\section{Conclusion}

- It is likely that the differences in course and origin are attributable to the racial group studied.

- As there is lot of variability in the origin of the CTN, mean values are not of much significance. The range of variability should be reported and knowledge of these to the cochlear implant surgeon, may help avoid inadvertent damage to the CTN.

- There is a positive correlation between the FR length, maximum width of FR and the angle between the FN and CTN.

- Facial recess length, angle between FN-CTN and the maximum width of the FR show higher values in pneumatized temporal bones as compared with sclerotic and diploic temporal bones. Facial recess length shows great- est variation depending on the type of pneumatization pattern.

- Variation in the origin of CTN and pneumatization pattern can influence the size of the FR.

- Round window exposure is obtained in all the cases through FR as it is wide enough at the level of the round window, but in some cases, when it is posteriorly placed, additional positioning of the table may be required.

- Preoperative identification by imaging may alert the surgeon and he may make necessary adjustments on the table to avoid nerve injury.

\section{References}

1 Franz BK, Clark GM, Bloom DM. Surgical anatomy of the round window with special reference to cochlear implantation. J Laryngol Otol 1987;101(02):97-102

2 Gudis DA, Montes M, Bigelow DC, Ruckenstein MJ. The round window: is it the "cochleostomy" of choice? Experience in 130 consecutive cochlear implants. Otol Neurotol 2012;33(09): 1497-1501

3 Richard C, Fayad JN, Doherty J, Linthicum FH Jr. Round window versus cochleostomy technique in cochlear implantation: histologic findings. Otol Neurotol 2012;33(07):1181-1187

4 Shapira Y, Eshraghi AA, Balkany TJ. The perceived angle of the round window affects electrode insertion trauma in round window insertion - an anatomical study. Acta Otolaryngol 2011;131 (03):284-289

5 Connor SE, Holland NJ, Agger A, et al. Round window electrode insertion potentiates retention in the scala tympani. Acta Otolaryngol 2012;132(09):932-937

6 Addams-Williams J, Munaweera L, Coleman B, Shepherd R, Backhouse S. Cochlear implant electrode insertion: in defence of cochleostomy and factors against the round window membrane approach. Cochlear Implants Int 2011;12(Suppl 2): S36-S39

7 Adunka OF, Dillon MT, Adunka MC, King ER, Pillsbury HC, Buchman CA. Cochleostomy versus round window insertions: influence on functional outcomes in electric-acoustic stimulation of the auditory system. Otol Neurotol 2014;35(04):613-618

8 Briggs RJ, Tykocinski M, Stidham K, Roberson JB. Cochleostomy site: implications for electrode placement and hearing preservation. Acta Otolaryngol 2005;125(08):870-876

9 Adunka OF, Buchman CA. Scala tympani cochleostomy I: results of a survey. Laryngoscope 2007;117(12):2187-2194

10 Gantz BJ, Turner CW. Combining acoustic and electrical hearing. Laryngoscope 2003;113(10):1726-1730

11 Martins GdeS, Brito Neto RV, Tsuji RK, Gebrim EM, Bento RF. Evaluation of Intracochlear Trauma Caused by Insertion of Cochlear Implant Electrode Arrays through Different Quadrants of the Round Window. BioMed Res Int 2015;2015:236364

12 Zernotti ME, Suárez A, Slavutsky V, Nicenboim L, Di Gregorio MF, Soto JA. Comparison of complications by technique used in cochlear implants. Acta Otorrinolaringol Esp 2012;63(05): 327-331

13 Liu L, Arnold R, Robinson M. Dissection and exposure of the whole course of deep nerves in human head specimens after decalcification. Int J Otolaryngol 2012;2012:418650

14 Trost O, Rouchy RC, Teyssier C, et al. CT-scan imaging of iron marked chorda tympani nerve: anatomical study and educational perspectives. Surg Radiol Anat 2011;33(06):515-521

15 Davies DV, Coupland RE in Gray's Anatomy, D.V. Davies, Ed., p. 1161, Longmans, Green, and Co, London, UK, 34th edition, 1967

16 Hamamoto M, Murakami G, Kataura A. Topographical relationships among the facial nerve, chorda tympani nerve and round 
window with special reference to the approach route for cochlear implant surgery. Clin Anat 2000;13(04):251-256

17 Öztürk K, Göde S, Çelik S, et al. Revisiting the Anatomy of the Facial Recess: The Boundaries of the Round Window Exposure. Balkan Med J 2016;33(05):552-555

18 Durcan DJ, Shea JJ, Sleeckx JP. Bifurcation of the facial nerve. Arch Otolaryngol 1967;86(06):619-631

19 Kullman GL, Dyck PJ, Cody DT. Anatomy of the mastoid portion of the facial nerve. Arch Otolaryngol 1971;93(01):29-33

20 Muren C, Wadin K, Wilbrand HF. Anatomic variations of the chorda tympani canal. Acta Otolaryngol 1990;110(3-4):262-265

21 Nager GT, Proctor B. Anatomic variations and anomalies involving the facial canal. Otolaryngol Clin North Am 1991;24(03):531-553

22 Yadav SPS, Ranga A, Sirohiwal BL, Chanda R. Surgical anatomy of tympano-mastoid segment of facial nerve. Indian J Otolaryngol Head Neck Surg 2006;58(01):27-30

23 Măru N, Cheiță AC, Mogoantă CA, Prejoianu B. Intratemporal course of the facial nerve: morphological, topographic and morphometric features. Rom J Morphol Embryol 2010;51(02):243-248

24 Zou T, Xie N, Guo M, Shu F, Zhang H. [Applied anatomy of facial recess and posterior tympanum related to cochlear implantation]. Lin Chung Er Bi Yan Hou Tou Jing Wai Ke Za Zhi 2012;26(10): 445-448

25 Haynes DR. The relations of the facial nerve in the temporal bone. Ann R Coll Surg Engl 1955;16(03):175-185

26 Minnigerode B. Mitteilung einer seltenen intratympanalen Abteilung der Chorda Tympani. Acta otolaryngologica 1965;59:20-22

27 Bosman DH. The distribution of the chorda tympani in the middle ear area in man and two other primates. J Anat. 1978;127(Pt 2):443-445

28 Histelberger WE, House WP. Acoustic neuroma diagnosis-external auditory canal hyperplasia as an early sign. Arch. Otolaryngol 1966;83:50-53

29 Low WKChorda tympani as landmark for facial nerve: racial considerations. In: Magnan J, Chays A (eds), Proceedings of the Sixth International Conference on Cholesteatoma and Ear Surgery, 2000, 621-623

30 Zhu Y, Tong B, Xu S, Liu Y, Duan M. [Applied anatomy of operation through posterior tympanum approach]. Lin Chung Er Bi Yan Hou Tou Jing Wai Ke Za Zhi 2008;22(19):867-870

31 Calli C, Pinar E, Oncel S, Tatar B, Tuncbilek MA. Measurements of the facial recess anatomy: implications for sparing the facial nerve and chorda tympani during posterior tympanotomy. Ear Nose Throat J 2010;89(10):490-494

32 Jeon EJ, Jun B, Song JN, Kim JE, Lee DH, Chang KH. Surgical and radiologic anatomy of a cochleostomy produced via posterior tympanotomy for cochlear implantation based on three-dimensional reconstructed temporal bone CT images. Surg Radiol Anat 2013;35:471-475

33 Diogo I, Walliczeck U, Taube J, Franke N, Teymoortash A, Werner J, Güldner C. Possibility of differentiation of cochlear electrodes in radiological measurements of the intracochlear and chorda-facial angle position. Acta Otorhinolaryngol Ital 2016;36(04):310-316

34 Su WY, Marion MS, Hinojosa R, Matz GJ. Anatomical measurements of the cochlear aqueduct, round window membrane, round window niche, and facial recess. Laryngoscope 1982; 92:483-486

35 Young YS, Nadol JB Jr. Dimensions of the extended facial recess. Ann Otol Rhinol Laryngol 1989;98:336-338

36 Wang L, Yang J, Jiang C, Zhang D. Cochlear implantation surgery in patients with narrow facial recess. Acta Otolaryngol 2013; 133:935-938

37 Wang LE, Xia J, Shen XX, Wang ZX, Wang W, Zhang DX. Retaining Chorda Tympani Nerve Integrity During Cochlear Implant Surgery. Chin Med J (Engl) 2015;128:2115-2118

38 Wang H, Shan X, Meng Z, Sun H, Zhao L. [Anatomical measurements and clinical applications through facial recess approach]. Lin Chung Er Bi Yan Hou Tou Jing Wai Ke Za Zhi 2013;27(13): 708-711

39 Vaid S, Vaid N, Manikoth M, Zope A. Role of HRCT and MRI of the Temporal Bone in Predicting and Grading the Degree of Difficulty of Cochlear Implant Surgery. Indian J Otolaryngol Head Neck Surg 2015;67(02):150-158

40 He X, Feng Y, Chen D, Mei L, He C, Cai X. [Study of the anatomy related to cochlear implantation guided by HRCT]. Lin Chung Er Bi Yan Hou Tou Jing Wai Ke Za Zhi 2011;25:433-435

41 Leong AC, Jiang D, Agger A, Fitzgerald-O'Connor A. Evaluation of round window accessibility to cochlear implant insertion. Eur Arch Otorhinolaryngol 2013;270(04):1237-1242

42 Lee DH, Kim JK, Seo JH, Lee BJ. Anatomic limitations of posterior tympanotomy: What is the major radiologic determinant for the view field through posterior tympanotomy? J Craniofac Surg 2012;23:817-820

43 Pendem SK, Rangasami R, Arunachalam RK, Mohanarangam VS, Natarajan P. HRCT Correlation with Round Window Identification during Cochlear Implantation in Children. J Clin Imaging Sci 2014; 31(04):70

44 Eby TL. Development of the facial recess: implications for cochlear implantation. Laryngoscope 1996;106(5 Pt 2 Suppl 80):1-7

45 Bielamowicz SA, Coker NJ, Jenkins HA, Igarashi M. Surgical dimensions of the facial recess in adults and children. Arch Otolaryngol Head Neck Surg 1988;114(05):534-537

46 Tian H, Zhang D. [The measurement of pneumatized mastoid and facial recess in cochlear implant recipients younger than three years old]. Lin Chuang Er Bi Yan Hou Ke Za Zhi 2006;20(10): 441-443

47 Lloyd SK, Kasbekar AV, Kenway B, Prevost T, Hockman M, Beale T, et al. Developmental changes in cochlear orientation implications for Cochlear implantation. Otol Neurotol 2010;31:902-907

48 McRackan TR, Reda FA, Rivas A, Noble JH, Dietrich MS, Dawant BM, et al. Comparison of cochlear implant relevant anatomy in children versus adults. Otol Neurotol 2012;33:328-334 